\title{
Choosing and using statistical sources in Criminology - What can the Crime Survey for England and Wales tell us?
}

\author{
Andromachi Tseloni ${ }^{1}$ and Nick Tilley ${ }^{2}$
}

\begin{abstract}
There is a wide range of sources that might fruitfully be used in criminological research. This article overviews the type of evidence used in research that has recently appeared in the British Journal of Criminology, gives examples of unobtrusive administrative data that have been used in recent projects, and focuses on a single data set, the Crime Survey for England and Wales, which covers a wide range of criminological topics. Finally, it will be suggested that criminologists may be missing opportunities to draw on valuable data sets that, though imperfect, may be useful to them in their research.
\end{abstract}

\section{Contributors' affiliations and addresses}

${ }^{1}$ Corresponding Author. Professor of Quantitative Criminology, School of Social Sciences, Nottingham Trent University, Burton street, Nottingham NG1 4BU, UK. Tel. +44 (0)115 8484704. E-mail andromachi.tseloni@ntu.ac.uk

${ }^{2}$ Professor, JDI, Department of Security and Crime Science, University College London, 35 Tavistock Square, London WC1H 9EZ, UK. Email n.tilley@ucl.ac.uk

\section{Brief Biographies}

Nick Tilley is a member of UCL's Jill Dando Institute of Crime Science. He is also an Emeritus Professor of Sociology at Nottingham Trent University and an Adjunct Professor in the Griffith Criminology institute in Brisbane. Long-term research interests include the global crime drop, programme evaluation methodology, situational crime prevention, and problemoriented policing.

Andromachi Tseloni leads the Quantitative and Spatial Criminology Research Group at NTU. She is a graduate of the Athens University of Economics and Business and the University of Manchester and has taught applied social statistics. Her research revolves around: crime victimisation; the crime drop; crime perceptions; social capital and cross-national comparisons.

Number of words: 8,713; Main text 6,926. 
Criminologists use a wide range of evidence types in their research. They do so in part because all types of evidence are fallible and it would be a mistake to depend on only a few kinds and in part because different research questions call for different types of evidence. The choice of evidence to draw on in practice is often also made on the basis of familiarity with data sources and with methods of their analysis.

In what follows we present first an account of the types of evidence that are currently used in British criminology before going on to suggest that there is scope for broadening the range of sources typically used, emphasising in particular the scope for making greater and better use of secondary ones. Finally we discuss in detail the scope for more use of victimisation surveys, focusing in particular on the Crime Survey for England and Wales (CSEW, previously known as the British Crime Survey). We also note ways in which this already high quality but underused resource could be further improved to allow for more informative and more useful criminological research.

\section{Evidence used in British criminology}

The evidence presented here for the types of evidence used in criminology is, in common with all evidence, fallible. The choice of evidence for types of evidence use was opportunistic and could certainly be improved. This was a quick and dirty look at the types of evidence that are constructed and drawn on in British criminology.

All journal articles that appeared in the British Journal of Criminology (BJC) from the first in 2013 to the penultimate in 2015 were scanned and coded for the original evidence that was assembled, analysed and reported ${ }^{\mathrm{i}}$. There were 163 articles in all. Of course a proportion of articles did not report research findings: 28 per cent comprised commentaries and half a dozen focused on theory and method. Moreover the BJC is an international journal, where many papers from non-UK institutions are published, many focus on crime issues in non-UK jurisdictions, and many are written by non-UK citizens. There was no way realistically to subdivide the papers into British and non-British and no comparison is made with journals published from other countries. Moreover, what is published in the BJC may in part reflect the predilections of the editor, editorial board and reviewers as well as decisions by authors on where to submit their work. This is, thus, at best a rough and ready account of what occurs in British criminology. For the purpose of this paper it was the best that was possible and provides at least indicative evidence of the types of evidence that are used in the UK's leading criminology journal. Others may like to repeat the exercise to see whether there have been changes over time and whether different evidence constellations are found in papers in journals published elsewhere.

So what do we find? Figure 1 shows the nationality of first author's institutional affiliation. The UK comes top and furnishes just under 40 per cent, with the US and Australia coming second and third, which is not surprising given that most residents in both have English as their first language. Figure 1 suggests that 'British' criminology figures large albeit not exclusively in the journal and it may well be that those submitting from other places do so in the belief that their work accords with the interests and methods used in British criminology. 
Figure 1 about here

The data types used in the published papers reporting findings is shown in Figure 2. Three quarters $(77 \%)$ used only one type of data, a sixth two (18\%), and the remainder three or more. Despite much talk of multiple methods they continue to be the exception.

It is clear from Figure 2, however, that a wide range of methods and data sources were used, but the interview was by far the most common means of collecting data. Of the 50 studies drawing on interviews, 40 per cent were relatively small scale with 30 or fewer participants where mainly qualitative methods of analysis would be possible (although ten had more than 100 and two more than 200). In all focus groups, observational studies, ethnography and the use of visual materials accounted for a quarter of methods used and would require mainly qualitative analysis (24\% of all data types drawn on in studies reporting research findings).

Figure 2 about here

There are plenty of examples of clever use of non-standard data sources, for example changing costs of cleaning buses as a measure of the effectiveness of an initiative aiming to reduce vandalism on buses (Poyner 1992); health records for sexually transmitted disease amongst the very young as an indicator of illicit sexual activity; hospital records as an indicator of levels of violent behaviour (Shepherd et al. 2006); police pre-existing interest in illegally parked cars in disabled driver bays as an indicator of generalized offending and antisocial behaviour (Chenery et al. 1999). The promise of unobtrusive measures of behaviour of interest has quite a long history in social science and has been advocated in the past for criminological research (Garwood et al. 2000). Exhibit one is drawn from current research in Australia by one of us to examine patterns of crime and antisocial behaviour in open spaces. The refuse collection department of the local authority has been using this form to code all items of rubbish being picked up in parks and other open spaces in one area on each collection day. This is being used as an indicator of patterns of behaviour occurring there and of changes occurring in them.

Exhibit 1 about here.

Equally there are plenty of examples of informative analyses of existing data sets. Secondary analysis of existing data sets, however, was used fairly infrequently in the BJC papers scanned over the past three years, occurring in less than a third of findings-reporting papers $(30 \%)$. Administrative data were drawn on around a sixth of papers reporting findings (16\%). Analysis of victimisation surveys appeared in only five papers, where we suggest there is scope for improvement both in use by criminologists and in the design of the CSEW in particular to create the potential for more informative analysis.

It is not the purpose of this paper to criticize the data sources created and used in papers published in the BJC. They have all clearly reached a standard where they have been accepted by a major journal. Rather, the suggestion being made here is that there may be much greater scope for conducting informative secondary analyses of data sets that have been created for administrative purposes, national scale survey research or which can be collected using administrative methods. 
Let us turn now to police recorded crime and the CSEW as the most frequently used sources of data on crime patterns and changes in them.

\section{Identifying and understanding crime patterns}

The main sources for crime statistics in the UK are police recorded crime data and crime survey data. The former includes basic information about crimes that have come to the attention of the police, such as, if known, time and place of incident, target's or victim's demographic information and perhaps employment, Modus Operandi of the offender, and any other evidence that may contribute to offender detection and criminal case solving.

\section{Police recorded crime data}

A number of limitations render police recorded crime unreliable as a source for measuring crime across jurisdictions and/ or over time. The most common limitations of police recorded crime include non-reporting by the public; non-standardised recording practice across police forces and over time; as well as changes in offence classification and legal definitions over time (Hough and Mayhew 1982; Van Dijk and Tseloni 2012). Police crime statistics have therefore been removed from those designated as 'National Statistics', whose statistical rigour is recognised by the independent UK Statistics Authority. This removal occurred in 2013, only a year after initial designation. With the following health warning, however, police recorded crime is still included in the Office for National Statistics (ONS) crime reports and publications alongside crime survey - based estimates (ONS 2016).

"In accordance with the Statistics and Registration Service Act 2007, statistics based on police recorded crime data have been assessed against the Code of Practice for Official Statistics and found not to meet the required standard for designation as National Statistics. Data from the Crime Survey for England and Wales (CSEW) continue to be badged as National Statistics" (ONS 2016).

\section{Crime surveys}

Crime surveys were initially introduced to supplement police recorded crime statistics. In addition to victims' crime experiences, police reporting and satisfaction, crime surveys provide information about a wide array of related issues - the general population's perceptions and attitudes about crime, disorder and the Criminal Justice System (CJS), including the police, as well as detailed demographic, socio-economic and other factual information about the survey participants, their household and neighbourhood.

The role of crime surveys however has expanded beyond 'counting crime'. The detailed knowledge on victim /target as well as non-victim characteristics conveyed by crime surveys has provided the foundations for theory development, especially on the topics of victimisation; fear of crime; and legitimacy of and trust in the CJS. For instance, the lifestyle, 
routine activities, social disorganisation and repeat victimisation strands of victimisation theory drew on (Farrell and Pease 1993; Hindelang et al. 1978; Reiss 1980; Sampson and Groves 1989) innovative crime survey data which enabled:

(i) Statistically reliable and detailed comparisons between victims and non-victims; and

(ii) Analyses of crime focused on the crime target or victim rather than the crime incident (which is the base of police statistics).

Population-based empirically evidenced theories (utilising crime survey data) have informed crime prevention policy interventions, such as those directing resources and police protection to repeat victims (Pease 1998; Pease and Tseloni 2014). Police analysts now routinely try to identify repeat victims within police recorded crime statistics.

\section{British Crime Survey}

The first national crime survey in the UK was the 1982 British Crime Survey (BCS). The 1982 BCS which was at the time an ad hoc survey did not have the '1982' attached to its name - it was simply the British Crime Survey. The BCS was initiated by the former Research and Planning Unit of the Home Office for England and Wales in mid-1981. The Scottish Home and Health Department followed suit and Scotland was added (Hough and Mayhew 1982). The BCS which measured crime in 1981 had at the time an uncertain future ii (as indicated by the lack of year in the title), a limited budget and unsurprisingly a small sample of roughly 10,000 respondents. "The full value of the survey statistics will accrue with repeats, when information about trends will become available. Until such time, the BCS can yield information only about 1981." (Hough and Mayhew 1982: 7). This is worth remembering especially given the media 'outrage' on crime rates 'hikes' when cybercrime was first measured in England and Wales last year (Watson 2015). The Home Office archived reports provide the justification for and detailed information on the first BCS findings. At the time of writing this the BCS has been in existence for over 30 years and evolved to the Crime Survey for England and Wales (CSEW). In what follows it will be referred to as the CSEW. A brief history and an overview of the topics currently covered by the CSEW is given in the next section.

\section{Other UK crime surveys}

Four crime surveys, in addition to the CSEW, currently exist in the UK. Scotland, which was included only in the first (1982) BCS, has had its own independent crime survey since 1993. That year the Central Research Unit of the Scottish Office conducted the first Scottish Crime Survey (SCS) independently of the BCS but with fairly similar sampling design to enable cross-national comparisons (Anderson and Leitch 1996). The SCS has now evolved to the Scottish Crime and Justice Survey (SCJS) which has been running continuously since 2008/09 and prior to that year on an ad hoc basis (Grant 2015). The Northern Ireland Crime 
Survey (NICS) which was introduced over 20 years ago has also run continuously since 2005 with just a few sweeps between 1994/95 and 2003/04 (Department of Justice 2015).

The Home Office has introduced two more crime surveys in addition to the CSEW: the Offending, Crime and Justice Survey and the Commercial Victimisation Survey. The Offending, Crime and Justice Survey (OCJS) is a longitudinal crime survey with rotated panel design with some new entries at each sweep examining both victimisation and selfreported offending of the general population. It was administered annually from 2003 to 2006. However high attrition rates have made the OCJS panel sample size inadequate for victimisation and offending studies.

The crime surveys discussed hitherto are based on population samples and cover individuals' and households' experience and perception of crime and related topics. The last survey mentioned here, the Commercial Victimisation Survey (CVS), examines businesses' crime experiences and prevention. The CVS which was initiated in 1993 and repeated in 2002 has been administered annually since 2012. The CVS has included the wholesale and retail sectors in all sweeps (although with changing definitions), but other sectors have been covered on an ad hoc basis. The full list of Home Office data sets is available at: http://www.esds.ac.uk/findingData/dephomeofficelist.asp?print=1 (accessed 3 February 2016).

Annual updates on the CSEW and the other UK crime surveys are provided at the Crime Surveys User Conference organised by the UK Data Service. Ad hoc presentations and updates on crime statistics, including crime survey data, are held at conferences and workshops organised by Learned Societies with such an interest. The most obvious interest groups include the Crime and Justice Statistics Network of the British Society of Criminology; the Social Statistics Section of the Royal Statistical Society and, last but not least, the Institute for Advanced Legal Studies which motivated this article - based on two presentations at the 2015 National Training Day: 'Sources and Methods in Criminology and Criminal Justice'. Virtual opinion and information exchanges, including responding to relevant UK Statistics Authority, Home Office, and the Ministry of Justice data - related consultations, also occur within the online JISCMAIL 'Crime-Justice-Stats' forum and the StatsUserNet 'Crime and Justice Statistics Network', both open to anyone with such an interest.

\section{Crime Survey for England and Wales}

\section{Short history and data sources}

The Crime Survey for England and Wales (CSEW, previously called the British Crime Survey) "is viewed as a gold-standard survey of its kind" (Flatley 2014: 199). It is a nationwide crime survey for England and Wales. As a repeated cross-section survey, it had been conducted in eight sweeps (1982, 1984, 1988, 1992, 1994, 1996, 1998 and 2000) before becoming an annual survey in 2001 (Kershaw et al., 2001). The CSEW was first administered by the former Research and Planning Unit, Research, Development and Statistics Directorate of the Home Office from 1981 until 2012. Following an independent 
review of official crime statistics by the National Statistician which had been requested by the Home Secretary, responsibility for crime statistics, including the CSEW, transferred from the Home Office to the Office for National Statistics (ONS) on 1st April 2012 (UK Statistics Authority 2010; Government Statistical Service 2011). The CSEW has been conducted by different survey companies over the years. These have been subcontracted by the Home Office Research and Planning Unit and, since 2011, the ONS. Primary data analysis is conducted in house while the companies prepare the survey reports.

Since its appearance, the CSEW has undergone a large number of improvements, such as changes in sample design, procedures, questionnaire content and collected information, and / or administrative responsibility for the survey. However welcome such changes may be they make a discussion of the CSEW without a specific time reference quite laborious. With apologies to the readers who are not interested in survey methodology the following overview is indispensable in order to appreciate what the CSEW data can or cannot tell us about crime and the CJS experiences and perceptions. It is only an overview - details about the CSEW sampling design, procedures and questionnaire over the years can be found in the respective technical reports (for example, Grant et al. 2006; Hales 1993; Hales and Stratford 1997; 1999; Hales et al. 2000; Kershaw et al. 2001; NOP Market Research Limited, 1985; 1989; Simmons and colleagues, 2002; White and Malbon, 1995; Wood, 1984) and the ONS User Guides from 2011/12 onwards (available at: http://www.ons.gov.uk/ons/guidemethod/method-quality/specific/crime-statistics-methodology/user-guides/index.html (accessed 4 February 2016). Flatley (2014) gives an excellent overview of the CSEW and the survey's impact on British criminological thinking and crime prevention policy.

\section{Population coverage and sampling frame}

The CSEW represents all England and Wales residents 16 or older and since 2009/10 also children aged 10-15 years old living in private accommodation. The CSEW sampling frame, a notional 'catalogue' of the population from which the sample is selected, has been the Postcode Address File since 1992 whilst prior to 1992 the Electoral Register was used. Therefore the survey's population coverage differs from the two nations' actual population. Students in university accommodation, pensioners in old people's care homes, disabled people in care homes, permanent residents in hotels or motels, members of staff and their families living in hospitals, prisons, schools etc., people living in trailers, homeless and children under the age of 10 are not covered by the survey.

\section{Sampling design, sample size and representativeness}

The CSEW uses a stratified multi-stage cross-section sample design, which (a) had overrepresentation of inner city ${ }^{\text {iii }}$ constituencies until 1998 and has had overrepresented low density areas since 2001/02, as well as (b) included ethnic minority booster samples until 1996. The random sample selection stages involve the following geographical strata:

selection of constituencies (prior to the $2000 \mathrm{CSEW}$ after first having divided them into inner 
city and non-inner city ones); within each selected constituency selection of postcode sectors; within each sector selection of segments; within each selected segment selection of addresses; and, in case of multi-occupancy selected addresses, selection of household. At the last stage one adult member per household is randomly selected by the interviewers to undertake the survey (since 1996 following the same methodology as in the 1992 sweep ${ }^{\text {iv }}$ and small variations in the remainder four sweeps, 1982-1988 and 1994).

In the survey's initial cross-sectional design the entire sample was introduced during the first quarter of the fieldwork year until 2000. Since 2001 the CSEW has used a continuous sampling design with monthly allocated interviews (Kershaw et al., 2001; Simmons and colleagues, 2002). Furthermore "the sample design has been refined in recent years to move to a partially clustered sample design involving an unclustered sample of addresses being drawn in the most densely populated areas, with more clustered designs in the medium population density and low population density areas" (Flatley 2014: 195).

The current CSEW sample size is roughly 35,000 households per year. However, as already mentioned it started with just under 10,000 interviews in 1982, roughly doubled in 2000, further increased to about 33,000 in 2001/02, then reached 45,000 interviews annually to ensure partial sample representativeness within Police Force Areas in 2004/05 and finally has dropped again to its current size since 2012/13.

The survey has consistent high response rates of $78 \%$ on average (Jansson 2007) albeit currently maintained at 70\% (Williams and Holcekova 2015). It represents the adult population in England and Wales with the caveats mentioned in the previous sub-section. To ensure this a number of weights (based on calibration of population estimates originally from the Labour Force Survey and currently the 2011 Census) are provided in the public domain CSEW data sets. Their purpose is to "adjust for the different selection probabilities involved in the respective [sample] designs" (Flatley 2014: 196). Thus they redress any population group non-randomness and non-representativeness introduced at (i) the first (prior to 2000 CSEW inner city and current Police Force Area weight) and (ii) last two stages of the sample selection process, including differential non-response (household and individual weights) as well as (iii) from the Home Office/ ONS crime counting rules (incident or series weight) (TNS 2014). The CSEW crime counting rules are overviewed in a later sub-section.

\section{Reference Period}

Prior to 2001 the CSEW reference period varied from about 12 to 15 months. Respondents were required to report any incidents that happened since first January of the year prior to the interview. Since the fieldwork period begun in January and the vast majority of interviews were conducted by the end of March [92.7\% (Hales, 1993: 13)], the reference period for most respondents was between 12 and 15 months. Events reported in the interview year were excluded from crime estimates for the reference year, although they were retained in the data for other uses than annual crime estimates. The continuous sampling design introduced since 2001 uses a rolling 12 month reference period. 
Events that occurred outside the reference period may however be reported because respondents in retrospective surveys, such as the CSEW, tend to 'forward telescope' events occurring before the reference period and report them as eligible events (Schneider 1981). A panel sample design can be used to 'bound' the reference period whilst respondents are asked to report events that happen 'since the last interview'. The CSEW does not employ a bounding procedure. Respondents are asked to date the events that they mention, but they are not offered a cognitive benchmark similar to a prior interview. Since 2001 the respondents have been offered a 'life event calendar', such as Christmas, Bank holidays, birthdays and other memory pinpoints, for the 12 months prior to their interview to help them place events in a meaningful way (Kershaw et al. 2001). Interviewers however have no listings of previous victimisation events against which to check reports in the current interview. 'Telescoping' would result in an overestimate of more serious events rather than more minor ones (Aye Maung 1995). The use of 'life event calendars' in the CSEW since 2001 in principle reduces 'forward telescoping' but how much has yet to be estimated (Kershaw et al. 2001).

\section{Mode of Interviews}

The CSEW was conducted via face to face interviews up until the 1992 sweep. Since 1994 Computer Assisted Personal Interviewing (CAPI) and for sensitive questions, such as domestic violence, Computer Assisted Self-administered Interviewing (CASI) has been implemented (Hales 1993; Hales and Stratford 1997; Hales et al. 2000; Kershaw et al. 2001; White and Malbon 1995). Information on the effects of computer assisted interviewing suggests that using computers in the interview process will lead to increases in the reporting of victimisation (Hubble and Wilder 1995). "Evidence from the USA suggests that there may be a slight rise in the recording of sensitive data" (White and Malbon 1995: 2). Indeed when CASI was implemented for questions about domestic violence in the 1996 CSEW the recorded prevalence of such incidents significantly increased (Mirrlees-Black 1999).

\section{Questionnaire Design and Content}

The CSEW questionnaire comprises the following parts: the Household Details (previously called Address File), the Main Questionnaire, the Demographics and Media Consumption Section, Special Modules (former Follow-up Questionnaires), the Victim Forms and ad hoc special topics modules.

The Demographic Section collects information about the characteristics of the respondent, his/ her household and the 'household representative person' (previously termed 'head of household'). It also asks about respondent's media consumption and sources of information on crime and related issues.

The Main Questionnaire collects information on crime experiences and perceptions - fear of and worry about crime, perceived incivilities and crime trends in the respondent's neighbourhood. In recent sweeps new forms of crime, such as mobile phone theft, plastic card and mass marketing fraud and cybercrime, are also investigated in the Main 
Questionnaire rather than the Victim Forms. This has been done in order to preserve the CSEW - based crime estimates time series' continuity and validity. Respondents aged 16-59 are currently asked about drugs and alcohol abuse, offending behaviour, domestic violence, sexual victimisation and its nature and stalking via a set of self-completion modules. Rotating self-completion modules have been recently introduced to cover the high demand for knowledge of specialist criminological topics without increasing interview length and associated survey's costs (financial and respondent fatigue).

The screening questions of the Main Questionnaire focus crime experiences and are organised so that there is a one to one correspondence between question and crime type. The screeners are designed to elicit mention of particular crime events, using the legalistic approach to screening (Cantor and Lynch 2000). Each question is designed to prompt mention of a particular type of crime event, e.g., burglary. All of the particulars necessary to classify the event as a specific type of crime are included in the screening question. As a result, the cues are embedded in long and complex sentences. One unintended consequence of this is the research-evidenced positive relationship between victimisation and education because more educated respondents are able to recognise, recall and report victimisation events (Hough 1987). The screeners also ask the respondent to report the number of occurrences of each crime type.

The selected household member for the CSEW interview reports about any type of crime against his/her household involving personal or household property, including motorvehicles, as well as any violent crime, theft or intimidation he/she has personally experienced. Until 1996 only female respondents were interviewed on incidents of sexual assault, rape, and obscene phone calls whereas all respondents thereafter.

Respondents who report crime experiences in the screener questions of the Main Questionnaire are then given up to $\operatorname{six}^{\mathrm{v}}$ further modules, the Victim Forms, to complete. Victim Forms are completed for crimes reported in reverse order of the screeners - that is the most serious crimes have priority over less serious ones. The descending order of crime seriousness is: rape and sexual assault, robbery, assault, theft from person, burglary, theft from dwelling, vehicle theft and vandalism (Hales 1993). In addition the CSEW includes data on threats, fraud and cybercrime which however are not part of the time series yet. Out of the six Victim Forms per victim the first three are long Victim Forms. They collect detailed information about the crime incident, its circumstances, offenders' modus operandi, related loss and /or harm, reporting to the police and reasons for non-reporting, the criminal justice system response to the crime and victim's satisfaction. A further three (short) Victim Forms collect less detailed information but sufficient to classify the incident for counting purposes. Back office checks ensure that the reported incident is correctly classified into one of the crime categories which also resemble as much as possible the statutory definitions of offences (TNS 2014: 58). This information is used to classify the incident as the most serious crime type that occurred during the event. ${ }^{\mathrm{vi}}$

This practice encourages full reporting (and counting) of the most serious and less common crime types without of course any guarantee in case of serious multiple victimisation. For this reason the screening questions of the Main Questionnaire have been used in the early CSEW 
- based academic work (Chenery et al. 1996; Osborn and Tseloni 1998). Indeed crimes can be analysed without using the data from the Victim Forms. It is important to keep in mind however that when using the screeners less serious crimes, which happened in the course of more serious ones and the respondent has not subsumed them in the latter, may be overcounted and crime types may be incorrectly defined. The next subsection discusses the crime types examined.

The Special Modules and former Follow-Up Questionnaires have been administered to different portions of the CSEW sample to maximise the number of themes covered. Prior to 2001/02 two partially or completely (depending on year) Follow-Up Questionnaires were administered to respective randomly selected sub-samples. These collected detailed information about attitudes and perceptions of respondents on concepts relevant to fear of crime and victimisation theories, such as lifestyle and routine activities, crime prevention measures, self-reported offending, attitudes towards and experience of the police, misfortunes, attitudes towards offenders' punishment etc. Apart from the Follow-Up questionnaires certain themes, such as self-reported drug use, sexual victimisation and young people crime experiences, were investigated in periodic questionnaire supplements. The increase of the sample size since 2001/02 has allowed the introduction of at least four questionnaire modules (administered to four randomly selected sub-samples) to explore topical issues, such as experiences of the police, attitudes to the Criminal Justice System, crime prevention and security, online security and anti-social behaviour (Downham 2015).

The CSEW for 10-15 years old is set out in the same way as the main survey, including the victimisation module, but the questions refer to schooling experiences, perceptions of crime, crime prevention and security. There is also a self-completion module covering bullying, street gangs, truancy and alcohol or drug use.

\section{Series}

Some crimes, such as domestic violence, are recurrent events that cannot be clearly distinguished. To overcome this, the CSEW classifies as series any repeat incidents which were very similar in that "the same thing was done under the same circumstances and probably by the same people" (Hales 1993: 12, Main Questionnaire, Appendix B). There is no threshold number of events required for invoking the series procedure but their number is truncated at five when used for calculating national crime rates. In addition only one Victim Form is completed for such recurrent victimisations, namely series, collecting information about the most recent event in the series.

\section{The way forward for the CSEW: The Users' perspective}

Based on the authors' and their colleagues (notably Professor Ken Pease and Professor Graham Farrell) past research a number of limitations of the CSEW have been identified which have hindered further in depth analyses and as a consequence limited potential insights 
for crime prevention policy. Particular suggestions for further improving the use of this already gem-like criminological data source are outlined in this section.

\section{Sample size}

It would be very helpful for the CSEW sample size to be large enough to be representative at the Police Force Area level. This would (a) facilitate local level policing, crime and crime perceptions research, (b) offer an abundance of practical policy and crime prevention insights at Local Authority level and (c) help with the Crime and Safety Partnerships and their PCCs budgets as they will not need to commission local victim surveys (usually of questionable quality, statistical standards and therefore usefulness).

\section{Survey methodology}

To facilitate repeat victimisation and crime seriousness escalation research, especially looking at transition probabilities of repeat victimisation the CSEW could incorporate a panel vii of respondents who are surveyed across different years. Keeping the same CSEW respondents across 2 or more years (waves) would offer ample insights on the above (and perhaps increase the rate of repeats).

\section{Sampling points - common across a range of central national social surveys}

Crime victimisation, its impact and seriousness, experience of ASB, other crime perceptions, attitudes towards the police and the criminal justice system and other CSEW examined topics are linked to individuals' and their areas' social capital (Sampson et al. 1997). Other measurements, such as political persuasion, for instance, are linked to attitudes and trust to the criminal justice system and punitiveness. A single survey examining all these issues is impossible due to respondents' fatigue and associated financial and quality costs. Other national surveys, such as the British Household Panel Survey, Understanding Society, and the Citizenship Survey, investigate various aspects of life that are arguably related to crime and crime perceptions. At the time of writing linked surveys exist but the CSEW is not one of them. Linking responses across comparable ONS surveys offers immense possibilities for social research, theory development and policy. The next paragraph provides a bit more information on social capital measurements.

\section{Questionnaire content}

The CSEW includes few social capital measurements ${ }^{\text {viii }}$ on an ad hoc basis notwithstanding their significance for informal 'guardianship', level of affinity felt to the area and resilience to victimisation. Social capital indicators refer to formal and informal connections between neighbours, citizens and their perceived access to local and /or national government's decision mechanisms. The theoretical aspects of social capital refer to bonding, bridging, 
trust, sense of community, social cohesion, social support and solidarity. Social capital constructs include: number of close friends that the respondent can rely on or confine in; number of friends to borrow money from; mutual aid or perceived solidarity which refers to helping the community in case of an emergency, as well as collective efficacy and collective mobilisation or non-formal social participation ix (Sampson 2006; Sampson et al. 1997).

Prior victimisation by burglary, car crime, and assault in the period before the reference year is the most important predictor of recent victimisation risk (Hope et al. 2001) and frequency (Osborn and Tseloni 1998) against victims with otherwise identical socio-demographic, economic, lifestyle, and area of residence characteristics. Do prior crime experiences indicate long-term victimisation which may be conceptualised similarly to long-term unemployment or simply a constellation of bad spells? However these questions were dropped after the 1992 sweep. Prior victimisation screener questions are important but far from perfect as the reported crime experience is not time - bounded (open to telescoping problems), validated or cross-checked. Using a panel element for examining repeat and multiple victimisation in depth, as suggested earlier, can address these problems.

Examining an abundance of individual and area information in relation to crime experience is one of the greatest advantages of crime survey data compared to police recorded crime. Past research on area characteristics (usually concurrent and interacting with individual and household ones) affecting victimisation risk and frequency (Osborn et al. 1992; Osborn and Tseloni 1998; Tseloni 2006; Tseloni and Pease 2015) as well as fear of crime (Brunton-Smith and Sturgis 2011) has relied appropriately on Census and police data. ${ }^{\mathrm{x}}$ Rich as it may be Census area profiling however lacks information on respondent's area of residence place or location use, such as residential or mixed use, and environmental clues. Information on distance from city centres and areas with concentrated leisure activities would also help explain victimisation. Interviewers' assessment and /or official data from ONS/ local authority on sample point 'place use' and distance from commercial and leisure activities centres would address the single limitation of CSEW compared to police recorded crime data for victimisation and situational crime prevention research.

A contested issue since the origins of the CSEW has been the measurement of fear of crime (Ditton and Farrall 2007; Sutton and Tseloni 2011). It has been shown that more exact wording and asking fear of crime questions in different sections of the questionnaire elicits responses that offer a more accurate picture of this issue (Farrall and Ditton 1999; Gray et al. 2008; Tseloni and Zarafonitou 2008).

For improving crime prevention CSEW- based insights the number of long Victim Forms could be increased from three so that detailed incident information may be gathered for and possible links made across more than three crimes per victim.

Finally, employing consistent questioning over time allows reliable time series not just for crime rates which is something the CSEW can be proud of, but also crime - related variables, such as routine activities and trust to the police and the criminal justice system. By contrast, absolute income levels are not comparable over time and in this case providing income data as quartiles would be more appropriate for time series. Further, new crimes are defined or 
emerge, such as the newly introduced law relating to domestic violence (Serious Crime Act Section 76, 2015), which includes coercive control and emotional abuse. To keep up with the signs of the time additional crime types within the CSEW could be introduced in a manner that does not affect existing time series.

\section{Substantive investigation}

The definition of series crimes is rather arbitrary and fits crime counting purposes rather than criminological theory and empirical research (Farrell and Pease 2007). A way forward is arguably an exploratory module for series victims to explore, for instance, how best they can be portrayed / counted within crime statistics; the risk or protective factors and causes of series victimisation in comparison to no, single, repeat or multiple victimisation; the consequences of series crimes on health, quality of life, employment opportunities etc.; whether perhaps series victims should be conceptualised and their needs accommodated in ways akin to those relating to individuals with long-term disability; and recommendations for potential avenues to prevention.

The escalation or not of crime seriousness during the same incident in composite crimes (Tseloni et al. 2010a) is another area worth exploring. It is important for crime prevention and harm reduction as demonstrated in the ample literature on situational risk and preventive factors for crime completion (versus attempt), seriousness and likelihood of injury. It would allow situational characteristics to be identified that would allow / limit / erase crime seriousness escalation and on that base inform context - specific advice that should be given to potential victims.

\section{Conclusion}

This paper has reviewed the kinds of data apparently most often used in British criminological research. It has argued that more use might be made of available data sources, rather than depending on the limited data collection resources that are often available to researchers. This is not to criticise published studies, only to suggest that some strong resources seem to be seldom used.

The paper went on to a more detailed discussion of national victimisation surveys, homing in on the Crime Survey of England and Wales (CSEW) as a particular example, which provides a rich array of data collected over some 30 years.

Although we are enthusiastic advocates for greater use of the CSEW in criminological research, the foregoing discussion makes clear a) that there is much devil in the detail and that the unwary therefore risk making misleading use of it and b) that there is substantial scope to improve this already excellent research resource.

To finish we have three recommendations. First, criminologists are advised to broaden their search for data sources on which to devise and test theories. Many potentially fruitful possibilities seem to be widely overlooked. There is scope for more imagination is using 
existing sources of information. Second, we recommend in particular that crime surveys are used as standard resources for criminological research and that those contemplating research careers should develop a good understanding of them and their possibilities. Third, we urge the custodians of victimisation surveys to facilitate their use and to canvass ways in which they could become ever more informative for criminological research. There is scope to improve an already strong resource. 


\section{References}

Anderson, S. and Leitch, S. (1996). Main Findings from the 1993 Scottish Crime Survey. Edinburgh: The Scottish Office Central Research Unit.

Aye Maung, N. (1995) Survey design and interpretation of the British Crime Survey. In Walker M. A., (ed.), Interpreting Crime Statistics. Royal Statistical Society Lecture Series 1, ch. 12. London: Oxford Science Publications.

Bourdieu, P. (1986) The forms of capital. In J. G. Richardson (Ed.), Handbook for theory and research for the sociology of education. New York: Greenwood. 241-258.

Brunton-Smith, I. and Sturgis, P. (2011) Do neighbourhoods generate fear of crime? An empirical test using the British Crime Survey. Criminology 49(2), 331-369.

Cantor, D. and Lynch, J.P. (2000) Self-report Surveys as Measures of Crime and Criminal Justice. In Criminal Justice 2000; Measurement and Analysis of Crime and Justice. Vol.4. Washington, D.C.: United States Department of Justice.

Chenery, S., Ellingworth, D., Tseloni, A. and Pease, K. (1996) Crimes which repeat: Undigested evidence from the British Crime Survey 1992. International Journal of Risk, Security and Crime Prevention, 1, 207-216.

Chenery, S., Henshaw, C. and Pease, K. (1999) Illegal Parking in Disabled Bays: A Means of Offender Targeting. Briefing Note 1/99. London: Home Office.

Department of Justice (2015) Northern Ireland Crime Survey. Available at: https://www.dojni.gov.uk/articles/northern-ireland-crime-survey (accessed 28 January 2016).

Ditton, J. and Farrall, S. (2007) The British Crime Survey and the fear of crime. In Hough, M. and Maxfield, M. (eds) Surveying Crime in the $21^{\text {st }}$ Century. Crime Prevention Studies. Vol. 22. Cullompton: Willan. 223-241.

Downham, L. (2015) 'Secondary analysis of the Crime Survey for England and Wales.' ONS Presentation at the Post-graduate Conference of the British Society of Criminology Conference, Plymouth, 3 July.

Farrall, S. and Ditton, J. (1999) Improving the measurement of attitudinal responses: An example from a crime survey. International Journal of Social Research Methodology 2, 5568.

Farrell G, Pease K (1993) Once bitten, twice bitten: repeat victimization and its implications for crime prevention. Crime prevention unit paper 46. London: Home Office.

Farrell G. and K. Pease. (2007) The sting in the tail of the British Crime Survey: Multiple victimisations. In Hough, M. and Maxfield, M. (eds), Surveying Crime in the 21st Century. Crime Prevention Studies. Vol. 22. Cullompton: Willan. 33-53.

Flatley, J. (2014) British Crime Survey. Encyclopedia of Criminology and Criminal Justice $(E C C J)$, Gerben Bruinsma and David Weisburd (Editors in Chief). New York: SpringerVerlag. 194-203. 
Garwood, J., Rogerson, M. and Pease, K. (2000) Sneaky measurement of crime and disorder. In V. Jupp, P. Davies and P. Francis (eds.) Doing Criminological Research. London: Sage. 157-167.

Government Statistical Service (2011) National Statistician's Review of Crime Statistics: England and Wales. Government Statistical Service. News Release. 6 June 2011. Available at: http://www.statisticsauthority.gov.uk/national-statistician/ns-reports--reviews-andguidance/national-statistician-s-reviews/national-statistician-s-review-of-crime-statistics.html (accessed 17 November 2015).

Grant, C., Harvey, A., Bolling, K. and Clemens, S. (2006) 2004-5 British Crime Survey (England and Wales) Technical Report Volume I. Prepared for: Research, Development and Statistics- Strategic Data Flows (Crime Reduction and Community Safety Group), Home Office March 2006. Available at: http://www.esds.ac.uk/doc/5347/mrdoc/pdf/5347userguide1.pdf (accessed 4 February 2016).

Grant, Neil (2015) 'The Scottish Crime and Justice Survey: Consistency and Change.' Crime Surveys User Conference, 11th December 2015. Available at: https://www.ukdataservice.ac.uk/media/604218/grant.pdf (accessed 28 January 2016)

Gray, E., Jackson, J. and Farrall, S. (2008) Reassessing the fear of crime. European Journal of Criminology 5(3), 363-380.

Hales, J. (1993) 1992 British Crime Survey (England and Wales) Technical Report. London: Social and Community Planning Research.

Hales, J. and Stratford, N. (1997) 1996 British Crime Survey (England and Wales) Technical Report. London: Social and Community Planning Research.

Hales, J. and Stratford, N. (1999) 1998 British Crime Survey Technical Report. London: Social and Community Planning Research.

Hales, J., Henderson, L., Becher, H. and Collins, D. (2000) 2000 British Crime Survey Technical Report (England and Wales). London: National Centre for Social Research.

Hindelang, M.J., Gottfredson, M.R., Garofalo, J. (1978) Victims of personal crime: an empirical foundation for a theory of personal victimization. Cambridge, MA: Ballinger.

Hope, T., Bryan, J., Trickett, A. and Osborn, D.R. (2001) The phenomena of multiple victimisation. British Journal of Criminology 41, 595-617.

Hough, M. (1987) Crime surveys and crime risks. Paper presented at the workshop on the design and use of the National Crime Survey. MD. July.

Hough, M. and Mayhew, P. (1982) The British Crime Survey: first report. A Home Office Research and Planning Unit Report. Home Office Research study No. 76. London: HMSO.

Hubble, D. and Wilder, B.E. (1995) Preliminary results from the National Crime Survey CATI experiment. Proceedings of the American Statistical Association, Survey Methods Section, New Orleans. 
Jansson, K. (2007) British Crime Survey - Measuring Crime for 25 Years. London: Home Office.

Long, A.D. and Perkins, D.D. (2007) Community social and place predictors of sense of community: A multilevel and longitudinal analysis. Journal of Community Psychology 35, $563-581$.

Kershaw, C., Chivite-Matthews, N., Thomas, C. and Aust, R. (2001) The 2001 British Crime Survey, First Results, England and Wales. Home Office Statistical Bulletin 18/01. London: Home Office.

Mirrlees-Black, C. (1999) Domestic Violence: Findings from a New British Crime Survey SelfCompletion Questionnaire. Home Office Research Study 191, London: Home Office Research and Planning Unit.

NOP Market Research Limited (1985) 1984 British Crime Survey Technical Report. Southampton: NOP.

NOP Market Research Limited and Social and Community Planning Research (1989) 1988 British Crime Survey (England and Wales) Technical Report. Southampton: NOP.

ONS (2015) Crime in England and Wales, year ending March 2015. Available at: http://www.ons.gov.uk/ons/rel/crime-stats/crime-statistics/year-ending-march2015/index.html (accessed 28 January 2016).

ONS (2016) Crime in England and Wales, year ending September 2015. Available at: http://www.ons.gov.uk/ons/rel/crime-stats/crime-statistics/crime-in-england-and-wales--year-ending-september-2015/index.html (accessed 3 February 2016).

Osborn, D.R. and Tseloni, A. (1998) The distribution of household property crimes. Journal of Quantitative Criminology 14, 307-330.

Osborn DR, Trickett A and Elder R (1992) Area characteristics and regional variates as determinants of area property crime levels. Journal of Quantitative Criminology 8, 265-285.

Pease, K. (1998) Repeat Victimisation: Taking Stock. Crime Detection and Prevention Series Paper No. 90. London: Home Office.

Pease, K. and Tseloni, A. (2014) Using modelling to predict and prevent victimisation. Springer-Brief Criminology Series, New York: Springer. ISBN: 978-3-319-03184-2 (Print) 978-3-319-03185-9 (Online).

Perkins, D. D., and Long, D. A. (2002) Neighbourhood sense of community and social capital: A multilevel analysis. In A. T. Fisher, \& C. C. Sonn (eds.) Psychological sense of community: Research, applications and implications. New York: Kluwer Press. 291-318.

Poyner, B. (1992) Video camera and bus vandalism. In R. Clarke (ed.) Situational Crime Prevention: Successful Case Studies. First Edition. New York: Harrow and Heston. 185-193.

Putnam, R. (1993) The prosperous community: Social capital and public life. American Prospect 13, 35-42. 
Putnam, R. (2007) E pluribus unum: Diversity and community in the twenty-first century. The 2006 Johan Skytte Prize Lecture. Scandinavian Political Studies 30, 137-174.

Reiss A.J. (1980) Victim proneness in repeat victimization by type of crime. In Fienberg S., Reiss A.J. (eds) Indicators of crime and criminal justice quantitative studies. Department of Justice, Washington, DC. 41-53.

Riger, S., and Lavrakas, P. J. (1981) Community ties: Patterns of attachment and social interaction in urban neighbourhoods. American Journal of Community Psychology 9, 55-66.

Sampson, R.J. (2006) Collective efficacy theory: lessons learnt and directions for future inquiry. In Cullen, F.T., Wright, J.P., Blevins, L. (eds) Taking stock: the status of criminological theory, advances in criminological theory, vol 15. Transaction Publishers, New 851 Brunswick, New Jersey. 149-167.

Sampson, R. J. and Groves, B. W. (1989) Community structure and crime: testing social disorganization theory. American Journal of Sociology 94, 774-802.

Sampson, R. J., Raundenbush, S. W., and Earls, F. (1997) Neighbourhoods and violent crime: A multilevel study of collective efficacy. Science 227, 918-924.

Simmons, J. and colleagues (2002) Crime in England and Wales 2001/2002. London: Home Office. July.

Shepherd, J. P., Sutherland, I. and Newcombe, R. G. (2006) Relations between alcohol, violence and victimization in adolescence. Journal of Adolescence 29(4), 539-553.

Schneider, A. (1981) Methodological problems in victim surveys and their implications for research in victimology. The Journal of Criminal Law and Criminology 72, 818-838.

TNS (2014) The 2013/14 Crime Survey for England and Wales Technical Report. Available at file://C:/Users/sgy3tseloa/Downloads/201314csewtechnicalreportvolumeone27112014_tcm7 7-388399.pdf (accessed 10 February 2016).

Tseloni, A. (2006) Multilevel modelling of the number of property crimes: Household and area effects. Journal of the Royal Statistical Society Series A-Statistics in Society 169, Part 2, $205-$ 233.

Tseloni, A. and Pease, K. (2015) Area and individual differences in personal crime victimisation incidence: The role of individual, lifestyle /routine activities and contextual predictors. International Review of Victimology 21(1), 3-29.

Tseloni, A. and Thompson, R. (2015) Securing the premises. Significance. London: The Royal Statistical Society 12(1), 32-35.

Tseloni, A. and Zarafonitou, C. (2008) Fear of crime and victimisation: A multivariate multilevel analysis of competing measurements. European Journal of Criminology 5(4), 387409.

Tseloni, A., Ntzoufras, I., Nicolaou, A. and Pease, K (2010a) Concentration of personal and household crimes in England and Wales. European Journal of Applied Mathematics, Special Issue on Mathematical Models for Criminality 21, 325-348. 
Tseloni, A., Zissi, A. and Skapinakis, P. (2010b) Psychiatric morbidity and social capital in rural communities of the Greek North Aegean islands. Journal of Community Psychology 38(8), 1023-1041.

Van Dijk, J. and Tseloni, A. (2012) Global Overview: International trends in victimisation and recorded crime. In van Dijk, J., Tseloni, A. and Farrell, G. (eds), The International Crime Drop: New Directions in Research, Hampshire: Palgrave Macmillan. 11-36.

UK Statistics Authority (2010) Overcoming barriers to trust in crime statistics: England and Wales. Monitoring Report 5, May 2010. London: Crown Copyright.

Watson, L. (2015) Crime soars $107 \%$ as cyber offences included for the first time - as it happened. The Telegraph. 15 October. Available at:

http://www.telegraph.co.uk/news/uknews/crime/11932670/Cyber-crime-fuels-70-jump-incrime-levels.html (accessed 3 February 2016).

White, A. and Malbon, G. (1995) 1994 British Crime Survey: Technical Report of a survey carried out by Social Survey Division for the Home Office. London: Office of Population Censuses \& Surveys, Social Survey Division.

Williams, J. and Holcekova, M. (2015) Assessment of the impact of a lower CSEW response rate. Crime Survey for England and Wales, Office for National Statistics, TNS BMRB Available at:

file:///C:/Users/Admin/Downloads/assessmentoftheimpactofalowerresponserateforcsewjuly20 15_tcm77-411588.pdf (accessed 28 March 2016).

Wood, D. (1984) British Crime Survey, 1982 Technical Report. London: Home Office.

Zissi, A., Tseloni, A., Skapinakis, P., Savvidou, M. and Chiou, M. (2010) Exploring social capital in rural settlements of an islander region in Greece. Journal of Community \& Applied Social Psychology 20(2), 125-138.

\section{Acknowledgements}

We thank Dr Charlotte Harris, Executive Director of the British Society of Criminology, and the organisers of the National Socio-Legal Training Day: Sources and Methods in Criminology and Criminal Justice for inviting us as well as the Editor of this journal, $\mathrm{Mr}$ David Wills, for sustained encouragement. Professor Ken Pease, Professor Graham Farrell, Professor Jim Lynch and the BCS /CSEW statisticians at the Home Office /ONS are gratefully acknowledged for lengthy discussions and tireless clarifications on the crime survey data over the years. 
Figure 1: Country of affiliation of first author, papers appearing in the British Journal of Criminology, 2013-2015

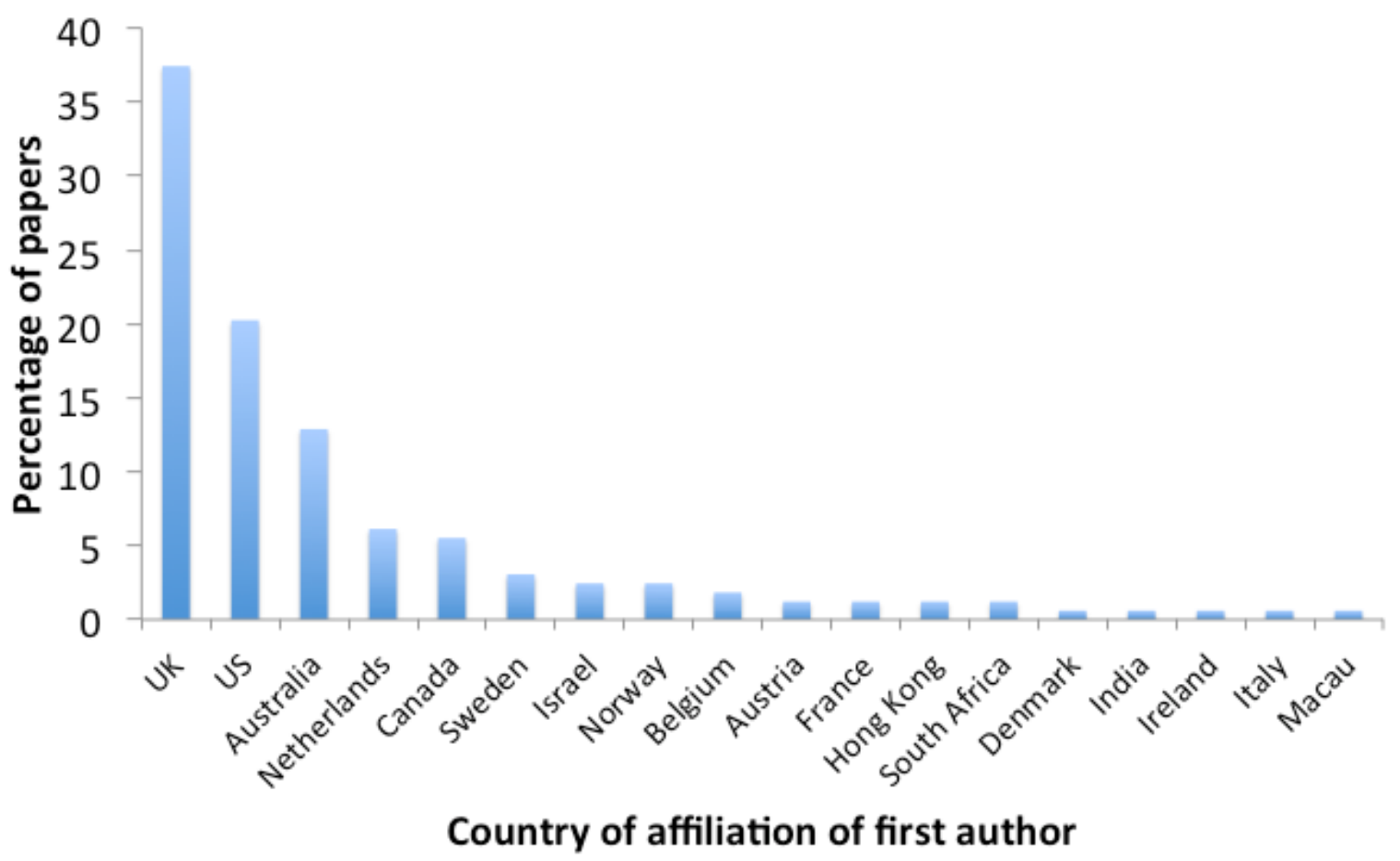


Figure 2: Types of data used in papers appearing in the British Journal of Criminology, 2013-2015

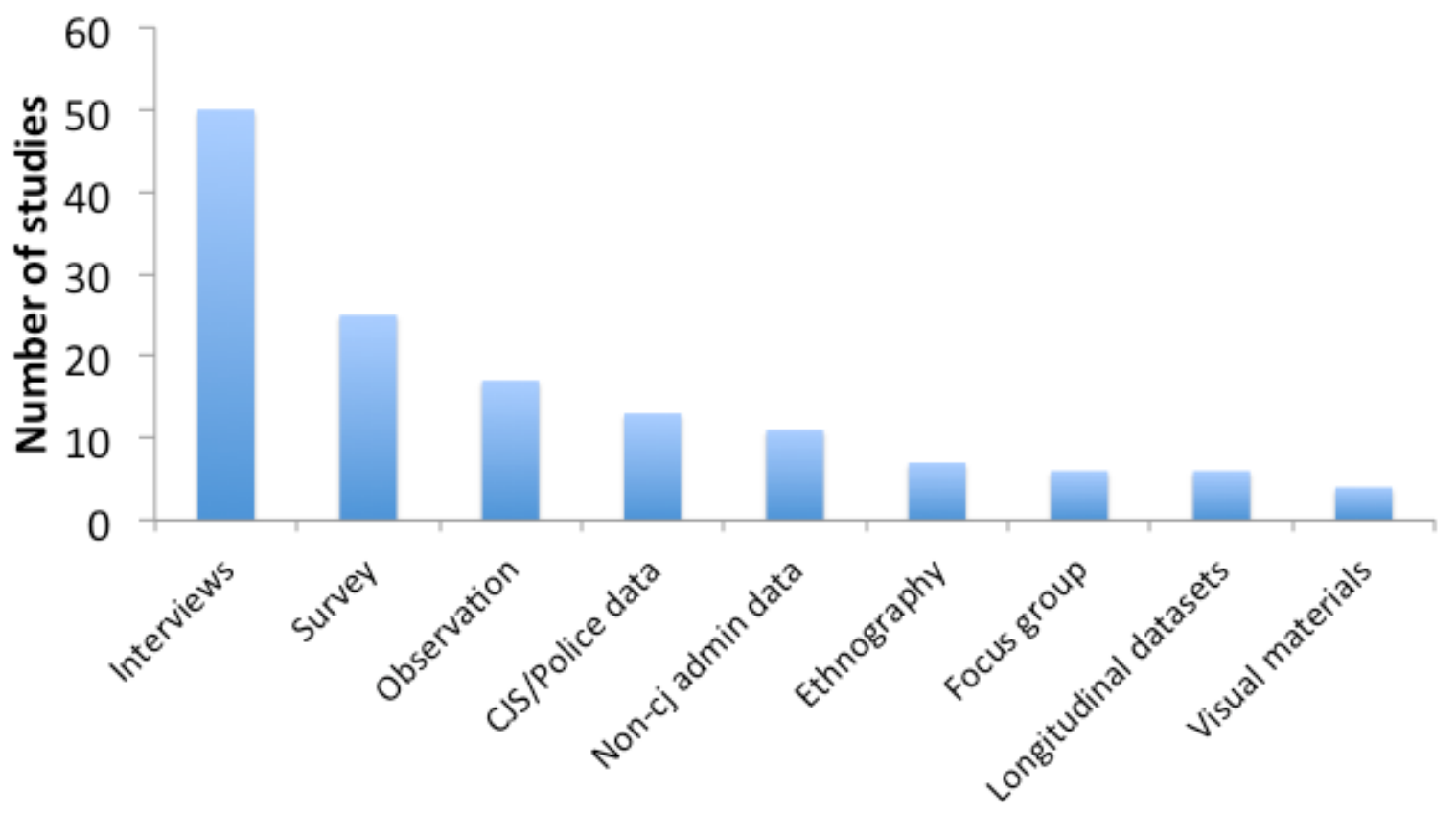

Types of data used 


\title{
Exhibit 1: Australian rubbish data collection form
}

\author{
Refuse Data Collection Instrument - Lakers Crew
}

This form is to be used by the Lakers Crew to record information about rubbish that is collected. One form is to be completed for each site, each week. The form should be started on Monday and finished and given to the Parks Supervisor on Friday. The four sites that are of interest are:

1. $X X X X X X X$

2. $x X X X X X X$

3. $x X X X X X X$

4. $X X X X X X X$

\section{Site Information}

Dates:

Site number/name:

No of syringes placed into sharps container

Were any goods of value found (i.e., purse/wallet, phone, sim car, key or debit cards?

If yes, please specify:

Number of shopping trollies observed at the site?

Rubbish Collected at Site

How many bags of rubbish were collected (i.e., $21 / 3,7 \frac{1}{2}$ )?

Please indicate the number of each item that was collected from the site:

\begin{tabular}{|l|l|l|l|}
\hline Rubbish: & $\begin{array}{l}\text { Number } \\
\text { collected }\end{array}$ & Rubbish & $\begin{array}{l}\text { Number } \\
\text { collected }\end{array}$ \\
\hline Drug use items: & & Sexual behaviour items: & \\
\hline Bongs (plastic containers or cans with holes) & & Condoms & \\
\hline Pieces of garden hose & & Condom packets / wrappers & \\
\hline Small clip seal bags (sappy bags) & Lubrication bottles / wrappers & \\
\hline Large clip seal bags & & Underwear (undies or bras) & \\
\hline Small pieces of aluminium foil & Tissues (used) & \\
\hline Cut or chopped straws & Other: & \\
\hline Spoon with burn marks underneath & & \\
\hline Spray paint cans & & Alcohol consumption items: & \\
\hline Spray deodorant cans & Beer cans & \\
\hline Plastic soft drink bottles with paint/paint stains & & Spirit cans & \\
\hline Glue / silicon container & & Glass beer bottles & \\
\hline Deodorant & & Alco-pop (Breezer, Cruiser) & \\
\hline Lighters & & Glass spirit bottles & \\
\hline Other: & Glass wine bottles & \\
\hline & Cask wine cartons, 'goon bags' or 'silver pillows' & \\
\hline Potential weapon items: & Brown paper bags from liquor store & \\
\hline Knives & & Beer or other alcoholic cartons & \\
\hline Scissors & & Beer bottle caps & \\
\hline Screw drivers & & Wine corks or screw tops & \\
\hline Wooden fence paling & Metho bottles & \\
\hline Wood with nails in it & Other: & \\
\hline Machete & & & \\
\hline Other: & & & \\
\hline
\end{tabular}

Additional Comments (i.e., specific area at site where there was a lot of rubbish; signs that party was held in park, damage to play ground, usual amount of rubbish at site, school holidays, etc.): 


\section{Endnotes}

${ }^{\text {i }}$ There was no inter-rater reliability check in this instance.
ii Personal communication with Pat Mayhew, OBE.
iii The definition of inner city has not been consistent across the CSEW sweeps. For instance,
in the 1992 CSEW those constituencies which had been included in the 1988 sample kept
their original classification. The ones introduced in 1992 were classified as inner cities if at
least one of the following applied: their population exceeded 50 persons per hectare, fewer
than $54 \%$ of households were owner occupiers, or fewer than $1 \%$ of household heads were
classified as professional or managerial (see the respective CSEW Technical Reports: Hales 1993; Hales and Stratford 1997, 1999; Hales et al. 2000; Kershaw et al. 2001; NOP Market Research Limited 1985, 1989; White and Malbon 1995; Wood 1984).

${ }^{\text {iv }}$ In case of multiple dwelling units at the address interviewers listed them in a systematic order (i.e., flat number) and selected one using the table of random numbers. After having selected the dwelling unit the interviewer listed the adults (16 or over) in alphabetical order of their first names and randomly selected one as the respondent. No substitution was permitted.

${ }^{v}$ The number of Victim Forms per victim used to be even smaller: four prior to the 1992 and five for the 1992 and 1994 CSEW rounds.

${ }^{\text {vi }}$ Crimes are classified according to attributes of the event, e.g. theft, attack, threat, into a variety of crime classes. If more than one crime is reported in a single incident, the event will be classified according to the most serious offence during the event.

vii The only panel - based national crime survey, the Offending Crime and Justice Survey, has not been maintained whilst the available 2003-2006 data include a rather small sample size across the waves due to high attrition for any meaningful research on victimisation let alone by specific crime types (and / or self-report offending).

viii The following presents a rough list of social capital questions during the lifetime of the BCS/ CSEW: Do neighbours help each other?; Would neighbours intervene if graffiti, fighting or rudeness? / Ask someone to pick up litter; Intervene with misbehaviour; Neighbourhood cohesion / Close community / Get on well; Do neighbours help each other? /Look out for each other; Influence on local decisions; Would neighbours participate if asked to solve local issue?; Involved in civil action; Volunteering including for neighbours; Do you trust neighbours? / Know people? / Would wallet get returned?; Like living here; Close friends /Relatives in the area; Borrow money at short notice; Find somewhere to stay the night at short notice.

${ }^{\text {ix }}$ In an ideal world all aspects of social capital ought to be examined within the CSEW to inform criminological inquiry and policy. For example, social capital would enable the nonlinear relationship between crime, tenure and security (Tseloni and Thompson 2015) to be unpacked. A significant body of literature is concerned with conceptualising and measuring social capital and related concepts (for instance, Bourdieu 1986; Long and Perkins 2007; Perkins and Long 2002; Putman 1993; 2007; Riger and Lavrakas 1981; Tseloni et al. 2010b; Zissi et al. 2010: 128-129). 
${ }^{\mathrm{x}}$ Using both individual characteristics and their aggregated responses over sampling points from the same data source does not offer additional independent insights on area effects, creates statistical errors and ought to be avoided. 